\title{
Identification of firefighting configuration of rural settlements
}

\author{
Anatoliy Tryhuba ${ }^{1, *}$, Roman Ratushny ${ }^{2}$, Oleg Bashynsky ${ }^{2}$, and Olexandr Shcherbachenko ${ }^{2}$ \\ ${ }^{1}$ Faculty of Mechanics and Energy, Lviv National Agrarian University, Ukraine \\ ${ }^{2}$ Department of surveillance and preventive activities, Lviv State University of Life Safety, Ukraine
}

\begin{abstract}
The method of identifying the objects of the firefighting system configuration of rural settlements of administrative territories has been improved. It involves the implementation of four steps on the identification of firefighting system configuration objects based on the use of geometric, statistical and regulatory approaches. The basic parameters of rural settlements of two characteristic territorial zones - the mountain formed on the basis of the fire part of the city of Turka and the flat, formed on the basis of the fire station of Mostyska town - are determined. The distribution of the area of the territories of two characteristic territorial zones and the number of inhabitants of their settlements, which are reflected by the theoretical law of Weibull, are established. The identification of road conditions between fire stations and border areas for the ten largest firefighting systems of rural settlements of Lviv region has been completed. It was established that the duration of fire and rescue firefighting movements on fire extinguishing is described by the theoretical law of Weibull distribution with the following characteristics: estimation of the mathematical expectation is $33.3 \mathrm{~min}$ and the estimation of the coefficient of variation is 0.54 .
\end{abstract}

\section{Introduction}

The current state of fire protection in rural regions of Ukraine, which arose as a result of the disbandment of a significant number of fire departments of former collective farms, can not be considered satisfactory. On the other hand, the lack of state financing of the industry does not allow to restore all structures in full. In view of this, it is necessary to find ways to maximize the level of fire protection. This, in particular, is intended to promote the "Integrated Program of Civil Protection of the Population and Territories of Lviv Oblast from Emergencies of Technogenic and Natural Characteristics for 2016-2018 years", according to which this work was carried out [1].

One of the most effective ways of high-quality implementation of the tasks set out in the program is to use a system approach and to take into account the characteristics of each fire extinguishing system [2].

The analysis of existing methods of identifying firefighting system configuration objects $[3,4,5]$ is proved that they have a number of shortcomings. In particular, they do

\footnotetext{
*Corresponding author: trianamik@gmail.com
} 
not take into account the interrelations between physical parameters and functional indicators of the objects of the configuration of fire extinguishing systems. In addition, it is not intended to take into account the specifics of the location of protection objects in rural settlements and the state of the network of roads between them and fire brigade formation.

Thus, the scientific and technical task that is solved in this work, namely the identification of the objects of configuration of fire extinguishing systems in certain administrative regions, is relevant both in applied and in scientific aspects.

\section{Method of identification of the objects of configuration of fire extinguishing systems}

The conceptual (descriptive) model of fire extinguishing systems of rural settlements of administrative areas developed in the paper [6] only conceptually defines the objects of configuration (components of fire extinguishing systems). This is not enough to design these systems, without disclosing the links between the parameters and indicators of the functioning of objects of their configuration, it is impossible to determine the effectiveness of both individual components and the entire fire-extinguishing system. Therefore, an integral part of the design of firefighting systems in rural settlements is the identification of their configuration objects.

The standard for project configuration management involves identifying the configuration objects in several steps: 1) identifying objects; 2) the establishment of their physical parameters; 3 ) the establishment of functional parameters of these objects [7]. The objects of the firefighting system configuration of rural settlements in administrative regions are actually defined during the development of their conceptual model. Some physical parameters are also indicated. At the same time, attention is not paid to the method that managers should use to set quantitative values of physical parameters and functional parameters of the objects of the configuration.

The method of identifying the objects of configuration of fire extinguishing systems of rural settlements is determined by the peculiarities of these objects. In particular, the physical parameters of such configuration objects as roads, settlements and fire trucks are special. Roads connecting fire and rescue formations with populated areas where fires arise, primarily characterized by distance between them and settlements. However, the territorial configuration of rural settlements (settlements) can be diverse, in particular, the elongated form. The fires in these points may occur in any part of them, which will determine the various distances between fire brigades and the place of fire. In view of this, the distance from the fire brigade to the location of the post office, or the village council of settlements, is first and foremost identified. At the same time, the distance between the fire-rescue units and one or another locality is divided into components that characterize the properties of this road (route) - distance with a hard covering - the main line; distance passing through settlements, etc. To determine these physical parameters (characteristics) of roads, a method is proposed based on the use of topological maps, kurvimeter, as well as available Internet data. By means of visual analysis of the composition of the road (route) between fire and rescue units and settlements, the boundaries of their respective components are determined. With the aid of a curvometer geometric method, the distances of these components are determined. With the help of the Internet, where information about the distances between settlements is stored, the total distance between the location of fire and rescue units and one or another locality is checked.

The physical parameters of settlements include the area of their territory, configuration, population. The configuration of these items determines their area. Determine the configuration of settlements is possible on the basis of a geometric method, which provides with a topographic map to visually indicate the set of their extreme points. The combination 
of all adjacent extreme points makes it possible to establish the geometric shape of one or another settlement, which characterizes its configuration. In addition, today on the Internet there is a resource with information on the area and the number of inhabitants of settlements [8], and therefore these parameters are determined on the basis of official data (Table 1).

Table 1. Approaches to the identification of objects of configuration of fire extinguishing systems.

\begin{tabular}{|c|c|c|}
\hline Name of object & Name of parameter & $\begin{array}{c}\text { Name of } \\
\text { approach }\end{array}$ \\
\hline \multirow{2}{*}{$\begin{array}{c}\text { Populated } \\
\text { points }\end{array}$} & The square of area & Official data \\
\cline { 2 - 3 } & Amount of dwellers & Official data \\
\cline { 2 - 3 } & Configuration & Geometric \\
\cline { 2 - 3 } Roads & General distance & Geometric \\
\cline { 2 - 3 } & $\begin{array}{c}\text { Segments with } \\
\text { different coatings }\end{array}$ & Geometric \\
\cline { 2 - 3 } & $\begin{array}{c}\text { Distance within } \\
\text { settlements }\end{array}$ & Geometric \\
\hline \multirow{2}{*}{ Fire tracks } & Speed on the road & Statistical \\
\cline { 2 - 3 } & Physical parameters & Normative \\
\hline \multirow{2}{*}{$\begin{array}{c}\text { Firefighters- } \\
\text { rescuers }\end{array}$} & $\begin{array}{c}\text { Duration of } \\
\text { preparation for } \\
\text { departure for a fire }\end{array}$ & $\begin{array}{c}\text { Normative- } \\
\text { statistical }\end{array}$ \\
\hline
\end{tabular}

Considering the process of preparing fire and rescue units before the departure of a fire, we note that this functional indicator is determined by the timing of the corresponding time. On this basis, appropriate standards are developed. At the same time, it should be noted that this process is the result of the interaction of firefighters and firefighters. The qualification of the firefighters and the structural features of fire vehicles determine the length of the process of preparing fire and rescue units before leaving for a fire.

The next process, which characterizes the functional characteristics of the configuration objects, is the process of traffic fire cars with firefighters and rescue vehicles equipped with fire extinguishing on the roads to the place of fire. These indicators are defined as the characteristics of the traffic lights, as well as the parameters of fire trucks and driver skills. As mentioned earlier, the roadways may differ in coverage, geometric parameters, the presence of other vehicles and obstacles on them. These physical parameters are determined during the identification of roads. They lie at the basis of the definition of such functional indicators of fire and rescue units, as the speed and duration of their movement on identified roads. The differentiated consideration of the speed and duration of fire and rescue units movements in relation to the branches of the roads on the basis of the use of the statistical method is an important reason for ensuring the adequacy of the simulation of the corresponding processes (Table 1).

The identification of deployment processes of fire and rescue units and fire extinguishing in our study is not considered. This is due to the peculiarities of the requirements of the mechanism of formation of the basic indicators of the value of the operation of fire extinguishing systems to their models. In particular, the requirements of this mechanism to the relevant models are such that they do not require consideration of these functional indicators in the strategic plans for the development of fire-fighting systems. In other words, these models do not need to take into account these indicators, because they are not conditioned by the structure of the fire extinguishing systems, but are determined by the parameters of combustion objects that are not related to the structural and parametric problems of the functioning of these systems. 


\section{Results of the identification of firefighting system configuration objects}

Settlements are characterized by the area and number of inhabitants. Their identification is carried out in order to find out the belonging to one of several alternative fire and rescue units. Typically, each settlement is characterized by the area of the territory it occupies, as well as the number of inhabitants living in it. Information about these two parameters exists today on the Internet [8]. Based on this information, we determined the empirical series of these parameters for two characteristic territorial zones of fire and rescue units - flat (on the example of the settlements of the Mostysky district) and mountainous (on the example of the settlements of the Turku district). The processing of these data by methods of mathematical statistics and probability theory made it possible to establish statistical characteristics of the distributions of the corresponding parameters. In particular, it was established that the area of settlements of these territorial zones is described by the theoretical law of the distribution of Weibull (Fig. 1-2).

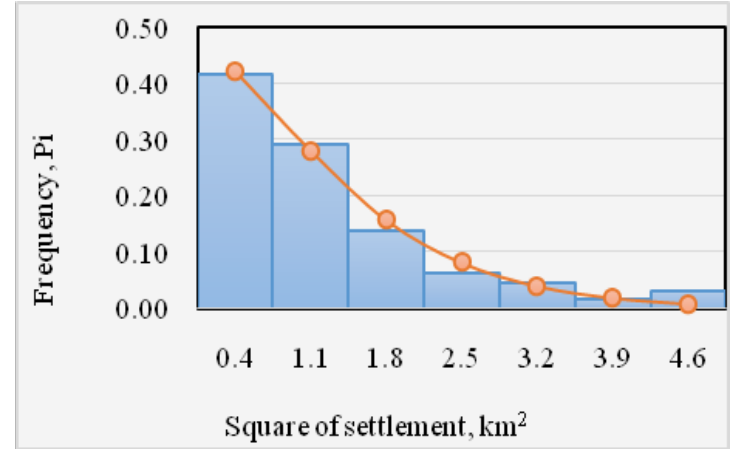

Fig. 1. Distribution of areas of settlements of Mostysky district.

In this case, estimates of mathematical expectation $\left(\bar{M}\left[S_{n n}\right]\right)$ and coefficient of variation $\left(\bar{v}\left[S_{\text {нn }}\right]\right)$ are respectively: for the flat territorial zone - $\bar{M}\left[S_{\text {нn }}\right]=1,28 \mathrm{~km} 2$, $\bar{v}\left[S_{\mu n}\right]=0,87$; for the mountainous territorial zone $-\bar{M}\left[S_{\text {ни }}\right]=1,82 \mathrm{~km} 2, \bar{v}\left[S_{\text {нn }}\right]=0,7$.

The mathematical analysis of empirical data on the number of inhabitants of the settlements of the two specified territorial zones made it possible to find that the distribution of the number of inhabitants is also reflected by the territorial distribution of Weibull (Fig. 3-4).

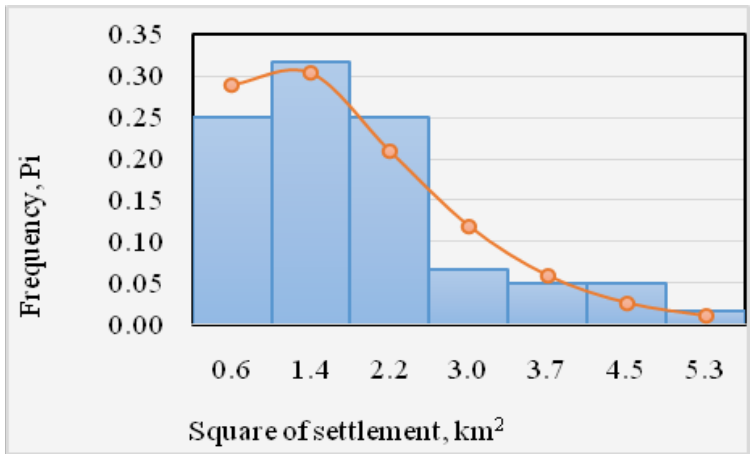

Fig. 2. Distribution of areas of settlements of the Turka district. 


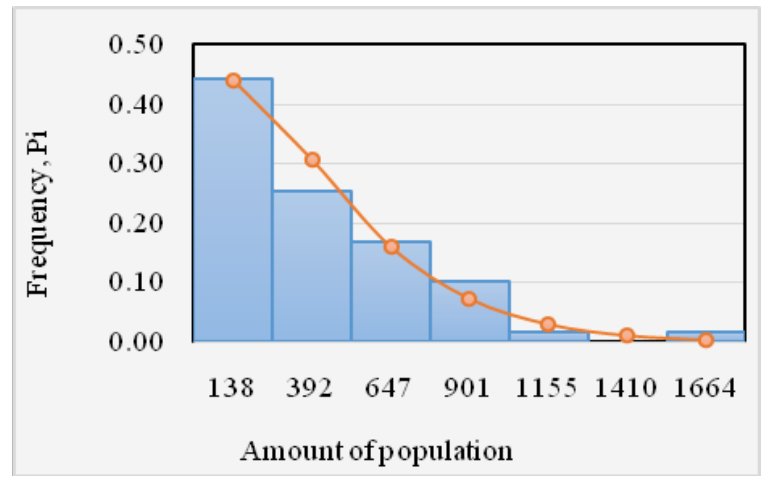

Fig. 3. Distribution of inhabitants of settlements of Mostysky district.

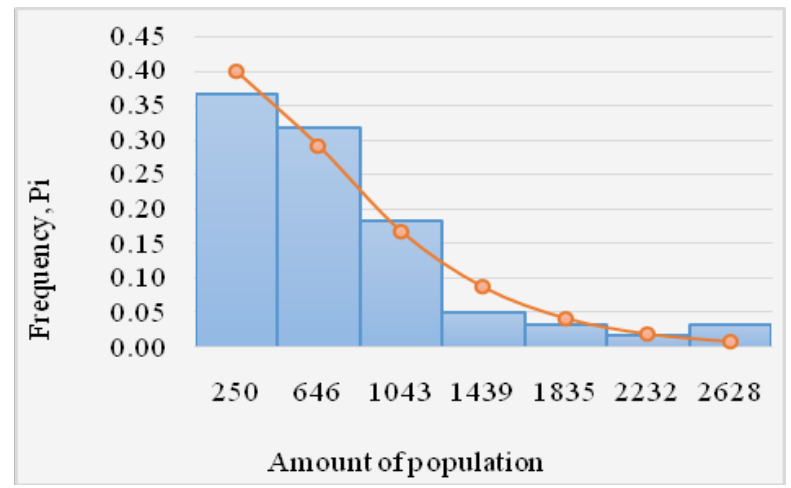

Fig. 4. Distribution of the population of settlements of the Turka district.

In this case, estimates of mathematical expectation $\left(\bar{M}\left[N_{\varkappa}\right]\right)$ and coefficient of variation $\left(\bar{v}\left[N_{ж}\right]\right)$ are respectively:

- for the plain territorial zone $-\bar{M}\left[N_{ж}\right]=409$ persons, $\bar{v}\left[N_{\varkappa}\right]=0,8$;

- for the mountainous territorial zone $-\bar{M}\left[N_{\varkappa}\right]=745$ persons, $\bar{v}\left[N_{\varkappa}\right]=0,82$.

Important for the project portfolio reengineering of the fire extinguishing system of rural settlements in administrative areas is information on the tightness of the link between the area of settlements and the number of people living in them. A correlation-regression analysis of the corresponding dependence carried out according to the standardized method testifies to the low level of this connection. In particular, for a flat territorial zone, the correlation coefficient between these values is 0.459 . For the mountainous territorial zone, this ratio is 0.496 .

Identification of settlements is one of the important stages in the search for projects to be included in the portfolio. However, the results obtained at this stage are not sufficient for the formation of portfolios of projects for the reengineering of fire extinguishing systems in rural settlements of administrative areas. To establish the level of fire insecurity of settlements as an indirect indicator characterizing the value of fire extinguishing systems, it is necessary to have information on the duration of extinguishing of objects, which is determined by the duration of the relocation of fire brigades from fire brigade units to the location of combustion objects. In view of this, the identification of the configuration of roads connecting settlements with fire rescue teams is an integral part of the administrative process of forming firefighting project portfolios. 
According to the current classification, highways are divided into highways, highway roads with improved coverage, hard roads, unpaved roads, ground, field and forest roads. In view of the fact that soil, field and forest roads are mostly used for transportation of garbage trucks and machine-tractor units, in our work we exclude their identification, and we focus on other types of roads for which the traffic of fire vehicles is considered.

Results of identification of distances between roads (routes) between the places of the territorial location of fire brigades and border settlements for the ten elementary fire extinguishing systems of rural settlements of Lviv region with the largest areas of their territorial zones of activity made it possible to perform their statistical analysis. In particular, the mathematical processing of the empirical data obtained made it possible to establish the following basic statistical laws: 1) the distribution and statistical characteristics of the total shortest distance of the roads connecting fire and rescue formation with border settlements; 2) the distribution and statistical characteristics of the number of settlements located on the way of fire and rescue units to the border settlements; 3) the distribution and statistical characteristics of the total distance of movement of fire and rescue units to the boundary settlements within the settlements; 4) the distribution and statistical characteristics of the distance of movement of these formations by the branches with the covering; 5) the distribution and statistical characteristics of the share of distance without coverage in the general way of movement of fire and rescue units to settlements. The results of relevant studies are summarized in Table 2.

Table 2. Results of statistical study of roads connecting fire stations with settlements.

\begin{tabular}{|c|c|c|c|c|}
\hline № & Name of road's & Parameter & \multicolumn{2}{|c|}{ Statistical parameters } \\
\cline { 4 - 5 } & parameter & distribution & $\begin{array}{c}\text { Average } \\
\text { number }\end{array}$ & $\begin{array}{c}\text { Coefficient } \\
\text { of variation }\end{array}$ \\
\hline 1 & $\begin{array}{c}\text { General shortest } \\
\text { distance, km }\end{array}$ & Weibull & 25,3 & 0,48 \\
\hline 2 & $\begin{array}{c}\text { Number of } \\
\text { settlements on the } \\
\text { way }\end{array}$ & Weibull & 4,4 & 0,52 \\
\hline 4 & $\begin{array}{c}\text { The total distance of } \\
\text { movement within the } \\
\text { settlements, } \\
\text { km }\end{array}$ & Weibull & 10,6 & 0,47 \\
\hline 5 & $\begin{array}{c}\text { Distance with } \\
\text { covering, km }\end{array}$ & Weibull & 22,9 & 0,49 \\
\hline 5 & $\begin{array}{c}\text { Distance without } \\
\text { covering, km }\end{array}$ & Weibull & 25,3 & 0,48 \\
\hline
\end{tabular}

Based on the identification of physical parameters of roads between fire brigades and border settlements, results have been obtained that make it possible to make another step on the way of forming a project portfolio by the indirect indicator (criterion) of the value of functioning of fire fighting systems - the level of fire insecurity of rural settlements.

This phase of portfolio management of the projects of re-engineering of fire extinguishing systems of rural settlements of administrative areas is called the evaluation of functional indicators of the objects of configuration, in particular, determining (predicting) the duration of the movement of fire and rescue units to settlements. The corresponding research is carried out on the basis of the physical parameters of the roads obtained as a result of their identification. The methodological feature of such a study is that the duration $\left(t_{p}\right)$ of the movement of said formations in a fire is determined by the logical formula:

$$
t_{p}=\sum_{\varphi} \bar{V}_{\varphi} \cdot L_{\varphi}
$$


where $L_{\varphi}$ is the distance of movement of fire and rescue formations along the road $\varphi$ of this category, $\mathrm{km} ; \bar{V}_{\varphi}$ - average speed of movement of these formations by the road $\varphi$ category, $\mathrm{km} / \mathrm{h}$.

Estimation of the duration $t_{p}$ of movement of fire and rescue units at the fire occurring in border settlements is made taking into account the different average speed of their movement on segments of the path belonging to different types. In particular, on the basis of the analysis of the results of the study of the velocity of the refueled vehicles (water), obtained in works, determined by their average speed on the segments of the path of different types: 1) for segments of the roads covered $\bar{V}_{\varphi}=57.8 \mathrm{~km} / \mathrm{h} ; 2$ ) for segments of roads with coverage within settlements $\bar{V}_{\varphi}=41,2 \mathrm{~km} / \mathrm{h} ; 3$ ) for segments without covering $\bar{V}_{\varphi}=35 \mathrm{~km} / \mathrm{h}$.

Based on the initial data on the identification of roads, the results of determination of their physical parameters, and also, taking into account the different speed of movement of fire and rescue units on segments of roads of different types, connecting the IF with the settlements, the corresponding calculations and the obtained results of determination of the duration of movement of the mentioned formations on fires to border settlements.

The mathematical processing of settlement data made it possible to obtain the basic statistical regularities of the indicators of the functioning of elementary fire extinguishing systems with the largest area of the territorial zones of the fire and rescue units of the Lviv region. In particular, it was established that the distribution of fire and rescue forces movement time at fire fires in boundary settlements is shown by the Weibull law, whose differential function has the form (Fig. 5):

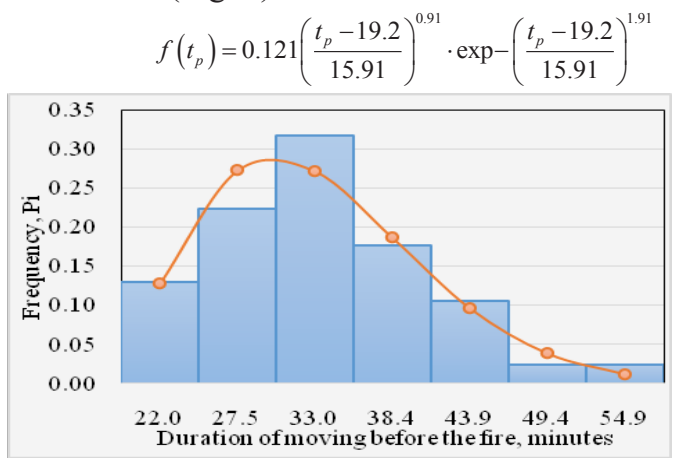

Fig. 5. Distribution of time of movement of fire and rescue units to extinguish fires in border settlements.

The statistical characteristics of this distribution are as follows: estimation of mathematical expectation $-M\left[t_{p}\right]=33.3 \mathrm{~h}$; estimation of the coefficient of variation $v\left[t_{p}\right]=0,54$. The structure of this time is distributed as follows: 1) the time of movement along the segments of the covered roads $-38 \%$; 2) time of travel on segments of roads with coverage within the settlements - 46\%; 3) time of movement along sections of roads without covering $-16 \%$. Thus, the identification of border settlements and highways of firefighting systems of rural settlements of Lviv region has made it possible to determine the basic physical parameters and functional parameters of fire and rescue forces movement in a fire for ten elementary fire extinguishing systems with the largest areas of the territorial zones of the existing IFs.

The results of statistical analysis of these parameters and indicators are the basis for the search for settlements with the maximum level of fire insecurity, which determine the 
potential projects of refinement portfolios of firefighting systems of rural settlements of Lviv region.

\section{Conclusions}

The analysis of existing methods for identification of configuration extinguishing systems indicates that they do not take into account the relationship between physical parameters and functional attributes of the configuration of fire extinguishing systems. They also do not include taking into account the specifics of the location of protecting objects in rural settlements and the condition of the network of roads between them and fire brigade formation. An improved method for identifying firefighting system configuration objects in rural settlements in administrative areas enables to determine the physical and functional parameters of these objects based on geometric, statistical and normative approaches.

Identification of settlements of two characteristic territorial zones - the mountain formed on the basis of the fire part of the city of Turka, and the flat, formed on the basis of the fire station of Mostyska, made it possible to statistically analyze their parameters. It is established that the distribution of the area of the territory and the number of inhabitants of settlements is reflected by the theoretical law of Weibull, and between these parameters the correlation connection is weak $(0,496$ and 0,459$)$, which determines the need for a detailed geometric modeling of the relationship between fire stations and settlements in order to establish them territorial membership of alternative elemental fire extinguishing systems.

Identification of roads between fire stations and border settlements for the ten largest firefighting systems of rural settlements in the Lviv region made it possible to perform a statistical analysis of their five main parameters (Table 2), which indicates their significant difference, which is the basis for a detailed analysis of each road between fire departments and settlements.

Estimation on the basis of a detailed approach to the speed of fire and rescue formations on different types of road sections, their duration of motion to extinguish fires enabled a statistical analysis of this duration, indicating that it is distributed according to the theoretical law of the Weibull distribution with the following characteristics: the estimation of mathematical expectation - 33.3 min and estimate of the coefficient of variation - 0.54 .

\section{References}

1. The complex program of civil protection of the population and territories of the Lviv region from emergencies of technogenic and natural character in 2016-2018 years, 12. Available online: http://lviv.dsns.gov.ua/ua/Programi.html (accessed on 23rd July 2018)

2. A. Tryguba, R. Ratushny, O. Shcherbachenko, O. Bashynsky, TEKA, 18, 5 (2018)

3. A. Tryguba, R. Ratushny, O. Shcherbachenko, Entrepreneurship and management, XIX, 2, 155 (2018)

4. O. Sydorchuk, R. Ratushny, A. Tryguba, Visnyk of Lviv State University of Life Safety, 10, 112 (2014) Available online:

https://journal.ldubgd.edu.ua/index.php/Visnuk/issue/archive (accessed on 28rd July 2018)

5. T. Ferreira, R. Vicente, A. Costa, R. Maio, Journal Of Cultural Heritage, 20, 739 (2016)

6. O. Sydorchuk, A. Tryguba, L. Sydorchuk, V. Bondarenko, Agroengineering research, 17, 3 (2013)

7. Practice Standard for Project Configuration Management, Project Management Institute, 53 (2007)

8. Wikipedia / Free encyclopedia. Available online: http://uk.wikipedia.org/wiki (accessed on 30rd July 2018) 